F. Reprod. Fert. (1971) 24, 153-160

\title{
BIOPHYSICAL CHARACTERIZATION OF FOWL SPERMATOZOA
}

\section{PRESERVATION OF MOTILITY AND FERTILIZING GAPAGITY UNDER GONDITIONS OF LOW TEMPERATURE AND LOW SPERM GONGENTRATIONS}

\author{
D. A. PISTENMA, N. SNAPIR*† AND H. C. MEL \\ Division of Medical Physics and Donner Laboratory, and \\ *Department of Poultry Husbandry, University of California, \\ Berkeley, California 94720, U.S.A.
}

(Received 10th Fune 1969, revised 29th Fuly 1970)

\begin{abstract}
Summary. The preservation of the motility and fertilizing capacity of fowl spermatozoa was evaluated under low temperature-low concentration conditions in low-ionic-strength glycine-citrate and glycine-phosphate buffers. Solutions of both buffers at 310 mosmol gave less than a $15 \%$ decrement from initial motility values after storage for $6 \mathrm{hr}$ at $3^{\circ} \mathrm{C}$ in concentrations from 8 to $80 \times 10^{6}$ spermatozoa $/ \mathrm{ml}$. Fertility results with spermatozoa diluted 1:30 in glycine-citrate buffer, stored for $1 \frac{1}{2}$ $\mathrm{hr}$ at $3^{\circ} \mathrm{G}$ and re-concentrated by centrifugation, did not differ from control values, using 1:2 dilution in modified Krebs' solution. These experimental media are thus proved capable of maintaining the vital functions of fowl spermatozoa during storage and for certain desired biophysical studies. They may, therefore, be of potential practical value for work in poultry husbandry and genetics.
\end{abstract}

\section{INTRODUCTION}

Study of the literature reveals that the motility and fertilizing capacity of fowl spermatozoa, in contrast to mammalian spermatozoa, can be maintained only for brief periods in media of high ionic strength during storage under conditions of (1) low temperature-high concentration, or (2) room temperaturelow concentration. These conditions are too restrictive for many desired studies such as those reported in Part II (Pistenma, Mel \& Snapir, 1971).

In this paper, we report a significant extension of the limiting experimental conditions of this kind, namely, the preservation of the motility and fertilizing capacity of fowl spermatozoa under the combined conditions of low temperature and low sperm concentrations in two low-ionic-strength (1/10) physiological media suitable for electrophoretic experiments. In addition, two high-ionicstrength (physiological) media are evaluated for storage of spermatozoa at low temperature and high concentrations.

† Present address: Department of Poultry Science, Faculty of Agriculture, Rehovoth, Israel. 


\section{MATERIALS AND METHODS}

Characteristics of ejaculates

The characteristics of the ejaculates from the White Leghorn roosters used in these experiments were as follows: volume, 0.4 to $1.0 \mathrm{ml}$; sperm concentration, 2.5 to $3.0 \times 10^{9} / \mathrm{ml}$; motility, $80 \%$ to $90 \%$ of spermatozoa show vigorous forward motion; fertilizing capacity, $85 \%$ to $95 \%$ with insemination of $0.1 \mathrm{ml}$ of normal undiluted semen at 4- to 5-day intervals.

\section{Sperm motility}

The customary grading of undiluted spermatozoa ranges from Grade I (extremely poor motility) to Grade VI (vigorous 'wave motion'). In addition, with low concentrations it was possible to estimate the percentage of individually motile spermatozoa and to utilize a scale of degrees of motility as follows: (1) immotile, (2) feeble tail movement. (3) vigorous tail movement, (4) feeble forward motion and (5) vigorous forward motion.

\section{Cooling spermatozoa}

Initial cooling of spermatozoa in all experiments was accomplished by adding an equal volume of dilution medium to pooled ejaculates in a 15-ml glass centrifuge tube. The stoppered tube was then placed in sawdust in a 2-1b coffee can. The can was covered and immersed to the brim in ice water. Gooling curves determined with a temperature recorder (Varian Associates) showed a temperature decrease from $29^{\circ} \mathrm{C}$ to $2.5^{\circ} \mathrm{C}$ in $120 \mathrm{~min}$, with a maximum cooling rate of $0.30^{\circ} \mathrm{C} / \mathrm{min}$.

\section{High-ionic-strength media}

Egg-yolk medium. The egg-yolk: glycine-citrate medium was a modification of that used by Bhattacharya (1962): $40 \%$ by volume whole egg yolk and $60 \%$ glycine-citrate solution consisting of $20 \mathrm{~g}$ sodium citrate dihydrate, $20 \mathrm{~g}$ glycine, $5 \mathrm{~g}$ fructose, $0.25 \mathrm{~g}$ citric acid, $1.5 \times 10^{6}$ units penicillin $\mathrm{G}$, diluted to $1000 \mathrm{ml}$ with distilled water.

Modified Krebs' solution. This was a modification of the Krebs'-HenseleitRinger solution used by Bhattacharya (1962): $0.9 \mathrm{~g} \mathrm{NaCl}, 0.5 \mathrm{~g} \mathrm{KCl}, 0.05 \mathrm{~g}$ $\mathrm{Na}_{2} \mathrm{HPO}_{4} \cdot 12 \mathrm{H}_{2} \mathrm{O}, 0.04 \mathrm{~g} \mathrm{MgSO}_{4}, 0.03 \mathrm{~g} \mathrm{NaHCO}_{3}, 0.5 \mathrm{~g}$ glucose, $10^{6}$ units penicillin $\mathrm{G}$, diluted to $100 \mathrm{ml}$ with distilled water and adjusted to $\mathrm{pH} 7.0$ with HCl.

\section{Low-ionic-strength media}

Glycine-citrate buffer. The solution consisted of $2.0 \mathrm{~g}$ sodium citrate dihydrate, $9.25 \mathrm{~g}$ glycine, $3.0 \mathrm{~g}$ fructose, $0.25 \mathrm{ml}$ of $10 \%$ citric acid solution, $48.6 \mathrm{~g}$ sucrose, $10^{6}$ units penicillin $\mathrm{G}$, diluted to $1000 \mathrm{ml}$ with distilled water; $\mathrm{pH} 6.94$.

Glycine-phosphate buffer. The solution consisted of $2 \cdot 2 \mathrm{~g} \mathrm{Na} \mathrm{NaPO}_{4} \cdot 12 \mathrm{H}_{2} \mathrm{O}$, $0.20 \mathrm{~g} \mathrm{NaCl}, 0.20 \mathrm{~g} \mathrm{NaHCO}_{3}, 0.016 \mathrm{~g} \mathrm{KH}_{2} \mathrm{PO}_{4}, 9.25 \mathrm{~g}$ glycine, $23 \mathrm{~g}$ fructose, $10^{6}$ units penicillin $\mathrm{G}$, diluted to $1000 \mathrm{ml}$ with distilled water and adjusted to $\mathrm{pH} 7 \cdot 1$ with $\mathrm{HCl}$.

Dextran (mol. wt 73,000; Sigma Chemical Company) or sucrose was added 
to the glycine-citrate and glycine-phosphate buffers in some instances to simulate density gradient conditions for electrophoretic experiments.

\section{RESULTS}

\section{Comparison of the two high-ionic-strength media}

Egg-yolk medium and modified Krebs' solution were evaluated for use in the initial dilution and cooling of fowl spermatozoa and for the temporary storage of spermatozoa re-concentrated after dilution in the low-ionic-strength buffers. Semen, obtained by abdominal massage (Burrows \& Quinn, 1939), was pooled, divided into two samples, diluted with equal volumes of egg-yolk medium or modified Krebs' solution and placed in separate 15-ml glass centrifuge tubes. Both samples were cooled continuously from room temperature to $4^{\circ} \mathrm{C} \mathrm{in} 2 \mathrm{hr}$, held at that temperature for a further $2 \mathrm{hr}$ and then allowed to warm naturally to room temperature. After warming, there were no apparent differences in morphology or in the high degree of motility of the spermatozoa in the two samples. Two groups of two chickens, all of proven high fertility, were inseminated with $0.1 \mathrm{ml}$ of the respective samples. The procedure was repeated twice

TABLE 1

PRESERVATION OF FERTILIZING CAPACITY OF FOWL SPERMATOZOA DILUTED $1: 2$ AND STORED IN HIGH-IONICSTRENGTH MEDIA AT $4^{\circ} \mathrm{C}$

\begin{tabular}{l|c|c}
\hline & Egg-yolk medium & Modified Krebs' solution \\
\hline Total no. of eggs & 33 & 40 \\
No. of fertile eggs & 3 & 32 \\
$\%$ of fertile eggs & $9 \cdot 1$ & 80 \\
\hline
\end{tabular}

with fresh spermatozoa at 4-day intervals and eggs were collected from the day after the first insemination until 4 days after the third insemination. The results are presented in Table 1 . Only $9.1 \%$ of the eggs were fertilized by spermatozoa stored in the egg-yolk medium compared to $80 \%$ fertilized in the modified Krebs' solution.

\section{Comparison of the two low-ionic-strength media}

Motility. The preservation of motility at $3^{\circ} \mathrm{C}$ in low-ionic-strength glycinecitrate and glycine-phosphate buffers was evaluated after adjusting their osmolarity with sucrose to 310,368 and 427 mosmol. Pooled semen was diluted 1:2 with modified Krebs' solution and cooled from room temperature to $3^{\circ} \mathrm{C}$ in $2 \mathrm{hr}$. Aliquots of each of the six solutions were then diluted to concentrations of $80 \times 10^{6}$ spermatozoa/ml. Additional dilutions were made on each of the suspensions resulting in concentrations of $40,27,20,13$ and $8 \times 10^{6}$ spermatozoa/ $\mathrm{ml}$, giving a total of thirty-six samples. Intermittent observations were made over the next few hours.

After $1 \mathrm{hr}$ at $3^{\circ} \mathrm{C}$, aliquots of selected 310-, 368- and 427-mosmol solutions of both buffers were allowed to warm to room temperature. Spermatozoa in 
the 310- and 368-mosmol solutions showed no change from their initial motility, while those in the 427-mosmol solutions exhibited a marked decrease in motility $(10 \%$-feeble forward motion; $15 \%$ to $20 \%$-feeble tail movement). The final observations at room temperature followed storage for $6 \mathrm{hr}$ at $3^{\circ} \mathrm{C}$. In the $310-$ mosmol buffer solutions, and at all six concentrations, approximately $70 \%$ of the spermatozoa still had vigorous forward motion. In the 368-mosmol buffer solutions, approximately $50 \%$ of the spermatozoa had vigorous forward motion and $20 \%$ exhibited vigorous tail movement. Moderately severe tail-to-tail agglutination occurred in all 368-mosmol solutions whereas agglutination was rare in the 310-mosmol solutions. In the 427-mosmol buffer solutions, less than $5 \%$ of the spermatozoa showed any degree of progressive motility.

In summary, there were no appreciable differences in the motilities of spermatozoa diluted with the various osmolar solutions of low-ionic-strength glycinecitrate and glycine-phosphate buffers. Both 310-mosmol solutions gave excellent preservation of motility; i.e. less than a $15 \%$ decrement from the initial values was observed, in concentrations ranging from 8 to $80 \times 10^{6} / \mathrm{ml}$ after $6 \mathrm{hr}$ storage at $3^{\circ} \mathrm{C}$.

Fertilizing capacity. In further experiments to assess the fertilizing capacity of spermatozoa in the low-ionic-strength media and modified Krebs' solution, pooled semen was diluted 1:2 with modified Krebs' solution and cooled to $3^{\circ} \mathrm{G}$ in $2 \mathrm{hr}$. One-third of the sample was further diluted in modified Krebs' solution to approximately $250 \times 10^{6}$ spermatozoa $/ \mathrm{ml}$ and stored at $3^{\circ} \mathrm{C}$ for $2 \frac{1}{2}$ $\mathrm{hr}$. The remainder of the sample was divided between two 40-ml glass centrifuge tubes, diluted with glycine-citrate or glycine-phosphate buffer to sperm concentrations of approximately $350 \times 10^{6} / \mathrm{ml}$, diluted further after $1 \mathrm{hr}$ to 80 to $90 \times 10^{6} / \mathrm{ml}$ and held at $3^{\circ} \mathrm{C}$ for an additional $1 \frac{1}{2} \mathrm{hr}$. This dilutionstorage protocol was repeated in 4 and 8 days. For each of the three trials, the six hens in each of the same three groups were inseminated. Eggs were collected from the day after the first insemination until 4 days after the third insemination. In the first trial, re-concentration of the diluted spermatozoa was not attempted because $2 \%$ dextran, simulating average density gradient conditions, interfered with the centrifugation process. Each hen was inseminated with approximately 1.0 $\mathrm{ml}$ of suspension containing 86 to $100 \times 10^{6}$ spermatozoa as indicated in Table 2A. In Trials 2 and 3 , where sucrose was used to represent the average gradient conditions, re-concentration of the spermatozoa in all three suspensions was accomplished by centrifugation (50 min at $400 \mathrm{~g}$ in Trial 2, 30 min at $1500 \mathrm{~g}$ in Trial 3). The volumes and total number of spermatozoa inseminated in Trials 2 and 3 are shown in Table 2B.

The results of Trial 1 are shown in Table 2A. It is seen that a much higher percentage of eggs was fertilized by spermatozoa diluted and stored in the glycine-citrate buffer than in either of the other two media. The differences between the fertilization rate of $56.3 \%$ with glycine-citrate buffer and the rates of $15.8 \%$ (glycine-phosphate) and $27.2 \%$ (modified Krebs' solution) are significant at the $P<0.01$ and $P=0.07$ levels, respectively, in a one-tail test (Goldstein, 1964).

The pooled results of Trials 2 and 3 are shown in Table 2B. The largest difference among the fertilization rates, i.e. that between the $41.9 \%$ in modified 
Krebs' solution and $26.5 \%$ in glycine-citrate buffer, is significant only at the $P=0.10$ level. The spermatozoa used in Trials 2 and 3 did exhibit increased evidence of certain morphological changes following centrifugation, the most common of which was severe bending of the spermatozoa to give apposition of head and proximal tail segments.

The average results of all three trials are given in Table $2 \mathrm{C}$. There is no difference between the fertilization rates with glycine-citrate buffer and modified Krebs' solution $(P \gg 0 \cdot 10)$. The fertilization rates with the glycine-citrate and glycine-phosphate buffers differ only at the $P=0.12$ level while the latter and the modified Krebs' solution differ at the $P=0.08$ level. Although any advantage of using the glycine-citrate buffer must be considered slight, it was selected for subsequent dilution studies.

\section{TABLE 2}

PRESERVATION OF FERTILIZING CAPACITY OF FOWL SPERMATOZOA DILUTED $1: 30$ AND STORED IN HIGH- AND LOW-IONIC-STRENGTH MEDIA AT $3^{\circ} \mathrm{c}$

\begin{tabular}{|c|c|c|c|}
\hline & \multicolumn{2}{|c|}{ Low-ionic strength } & \multirow{2}{*}{$\begin{array}{c}\begin{array}{c}\text { High-ionic } \\
\text { strength }\end{array} \\
\begin{array}{c}\text { Modified Krebs' } \\
\text { solution* }\end{array}\end{array}$} \\
\hline & $\begin{array}{c}\text { Glycine-citrate } \\
\text { buffer* }\end{array}$ & $\begin{array}{c}\text { Glycine-phosphate } \\
\text { buffer }\end{array}$ & \\
\hline $\begin{array}{l}\text { A. Trial 1: (No re-centrifugation) } \\
\text { Inseminate: } \\
\text { Volume (ml) } \\
\text { Total spermatozoa } \\
\text { Total no. of eggs } \\
\text { No. of fertile eggs } \\
\% \text { of fertile eggs }\end{array}$ & $\begin{array}{l}1 \cdot 0 \\
86 \times 10^{6} \\
16 \\
9 \\
56.3\end{array}$ & $\begin{array}{l}1 \cdot 0 \\
95 \times 10^{6} \\
19 \\
3 \\
15 \cdot 8\end{array}$ & $\begin{array}{l}1 \cdot 0 \\
100 \times 10^{6} \\
11 \\
3 \\
27 \cdot 2\end{array}$ \\
\hline $\begin{array}{l}\text { B. Trials } 2 \text { and 3: (Re-centrifugation) } \\
\text { Inseminate: } \\
\text { Volume (ml) } \\
\text { Total spermatozoa } \\
\text { Total no. of eggs } \\
\text { No. of fertile eggs } \\
\% \text { of fertile eggs }\end{array}$ & $\begin{array}{l}0 \cdot 2 \\
220 \times 10^{6} \\
34 \\
9 \\
26.5\end{array}$ & $\begin{array}{l}0.2 \\
210 \times 10^{6} \\
30 \\
9 \\
30\end{array}$ & $\begin{array}{l}0 \cdot 1 \\
150 \times 10^{6} \\
31 \\
13 \\
41 \cdot 9\end{array}$ \\
\hline $\begin{array}{l}\text { C. Average of Trials } 1,2 \text { and } 3 \\
\text { Total no. of eggs } \\
\text { No. of fertile eggs } \\
\% \text { of fertile eggs }\end{array}$ & $\begin{array}{l}50 \\
18 \\
36\end{array}$ & $\begin{array}{l}49 \\
12 \\
24-5\end{array}$ & $\begin{array}{l}42 \\
16 \\
38 \cdot 1\end{array}$ \\
\hline
\end{tabular}

* Six hens in each group.

\section{Comparison of best high-and low-ionic-strength media at 1:30 dilutions}

The effects of moderate dilution in modified Krebs' solution and in glycinecitrate buffer on the fertilizing capacity of fowl spermatozoa were compared, using a $1: 2$ dilution control. Pooled semen was diluted $1: 2$ in modified Krebs' solution and cooled from room temperature to $3^{\circ} \mathrm{G}$ in $2 \mathrm{hr}$. One-third of the sample (the control) was stored at this temperature without further dilution. The remainder was divided equally between two $40-\mathrm{ml}$ glass centrifuge tubes and diluted 1:30 with either modified Krebs' solution or glycine-citrate buffer. After $1 \mathrm{hr}$, the samples were re-concentrated by centrifugation for $50 \mathrm{~min}$ at 
$250 \mathrm{~g}$ with recovery of 85 to $90 \%$ of the spermatozoa. After removal of the supernatant, both samples of spermatozoa were re-suspended in modified Krebs' solution. This dilution-storage protocol was repeated 3 days later. On each occasion, the six hens in each of the same three groups were inseminated with $0.2 \mathrm{ml}$ of suspension containing approximately $200 \times 10^{6}$ spermatozoa. Eggs were collected from the day after the first insemination until 7 days after the second insemination. The results are shown in Table 3. There were no significant differences between the three fertilization rates.

TABLE 3

EFFEGTS OF DILUTION AND MEDIA ON THE PRESERVATION OF THE FERTILIZING GAPACITY OF FOWL SPERMATOZOA STORED AT $3^{\circ} \mathrm{G}$

\begin{tabular}{l|c|cc}
\hline & \begin{tabular}{c} 
Low-ionic strength \\
\cline { 2 - 3 }
\end{tabular} & \multicolumn{2}{|c}{ High-ionic strength } \\
\cline { 2 - 4 } & $\begin{array}{r}\text { Glycine-citrate } \\
(1: 30 \text { dilution })\end{array}$ & $\begin{array}{c}\text { Modified Krebs' solution } \\
(1: 30 \text { dilution })\end{array}$ & $(1: 2$ dilution $)$ \\
\hline Total no. of eggs & 34 & 46 & 38 \\
No. of fertile eggs & $20^{*}$ & 23 & 24 \\
$\%$ of fertile eggs & $58 \cdot 8$ & 50 & $63 \cdot 2$ \\
\hline
\end{tabular}

* Three of twenty eggs contained dead embryos whereas all other fertile eggs contained viable embryos on the 17 th day of incubation.

\section{DISGUSSION}

\section{Dilution and sperm concentrations}

Many investigators have studied the effects of cooling or dilution of fowl spermatozoa but not combinations of the two factors. Van Wambeke (1967) observed almost no loss in the fertilizing capacity of fowl spermatozoa diluted with equal volumes of either of two diluents containing skimmed milk and stored at 2 to $5^{\circ} \mathrm{C}$ for $24 \mathrm{hr}$. Even though the semen was diluted $1: 2$, the cell concentration was high in the sense used in this paper. Lorenz (1959), in his review, mentioned work by others at room temperature which showed the following: (1) 1:3 dilution with seminal plasma gave a slight decrease in fertility but no additional loss was observed with dilutions of up to $1: 63$, provided that the same number of spermatozoa was inseminated; (2) dilutions of up to $1: 50$ in an artificial medium resulted in only a slight loss of fertility for inseminations of at least $10^{8}$ spermatozoa; poor results were obtained with greater dilutions or with insemination of fewer spermatozoa and (3) 1:250 dilution in saline or in Tyrode's or Baker's solutions produced immediate irreversible immobilization. Even though fertilization capacity was preserved with dilutions up to $1: 63$, the media used are electrochemically unsuited for electrophoretic experiments.

The fertilization rate of $80 \%$ achieved with spermatozoa diluted $1: 2$ in modified Krebs' solution (Table 1) hardly differs from the optimum range of $85 \%$ to $95 \%$ expected in our experiments. The slight difference might be due entirely to the cooling to $4^{\circ} \mathrm{C}(2 \mathrm{hr})$ and storage at $4^{\circ} \mathrm{C}(2 \mathrm{hr})$. The difference between the fertilization rates of $80 \%$ (Table 1 ) and $63.2 \%$ (Table 3 ), with $1: 2$ 
dilutions in modified Krebs' solution and storage under the same conditions, is attributed primarily to using young hens of unknown fertility in the latter study. Modified Krebs' solution is superior to egg-yolk medium not only in preserving fertilizing capacity (Table 1), but also, for our physical studies, by being clear, colourless and of low viscosity. By contrast, egg-yolk medium exhibits decreased light transmission, and has a high viscosity as well as a potential for coating equipment with a protein film-all undesirable properties in certain experimental systems. This problem would also be expected with the skimmed milk medium used by Van Wambeke (1967).

In the study summarized in Table 3 , the fertilizing capacity of spermatozoa diluted $1: 30$ in low-ionic-strength glycine-citrate buffer, stored for $1 \frac{1}{2} \mathrm{hr}$ at $3^{\circ} \mathrm{C}$ and re-concentrated by centrifugation is comparable to that obtained for spermatozoa diluted $1: 2$ in modified Krebs' solution and stored under the same time-temperature conditions without centrifugation. This suggests that fowl spermatozoa can withstand the stresses (low-ionic strength, low temperature, moderate dilution and re-concentration by centrifugation) expected in preparative Staflo electrophoresis experiments using this buffer and that such experiments could be used to exploit information obtained in analytical studies.

Comparison of the fertility data in modified Krebs' solution (Table 3), reveals no difference $(P>0 \cdot 10)$ between the $1: 30$ dilution (with centrifugation) and the $1: 2$ dilution (no centrifugation). Thus, if use of a clear high-ionicstrength medium is indicated, modified Krebs' solution could be used for studies with fowl spermatozoa under conditions of moderate dilution.

Osmolarity. Storage of fowl spermatozoa in concentrations ranging from $8 \times 10^{6}$ to $80 \times 10^{6}$ spermatozoa $/ \mathrm{ml}$ preserved the sperm motility significantly better in 310-mosmol solutions than in 368- or 427-mosmol solutions for both glycinecitrate and glycine-phosphate buffers. As shown in Table 2, the fertilizing capacity was preserved after storage for $2 \mathrm{hr}$ at $3^{\circ} \mathrm{C}$ at $1: 30$ dilutions in 310mosmol solutions of both buffers. Preservation of fertilizing capacity in 368- and 427-mosmol solutions of these buffers was not evaluated because very poor fertilization rates were obtained in other fowl and rabbit work after the insemination of spermatozoa of poor motility (Pistenma, 1970). Reports for other media of different optimum osmolarities for the preservation of motility and of fertilizing capacity-300 and 350 mosmol, respectively (Lorenz, 1959)make it clear that osmolarity cannot be considered a variable independent of medium.

The marked decrease in motility, after $1 \mathrm{hr}$ at $3^{\circ} \mathrm{C}$, for all sperm concentrations in the 427-mosmol glycine-citrate and glycine-phosphate buffers is in contrast with the excellent preservation of motility for $4 \mathrm{hr}$ in the 415-mosmol egg-yolk medium. Egg yolk is known to protect spermatozoa against the adverse effects of high osmolarity on motility, which may be well preserved in this medium for more than $24 \mathrm{hr}$. In spite of this, the observed loss of fertilizing capacity (Table 1 and Lorenz, 1959) suggests that spermatozoa sustained irreversible damage during the 4-hr exposure to egg-yolk medium. (The probable dilution and/or absorption of the medium in the female genital tract should have largely eliminated the influence of the medium shortly after artificial insemination.) It is recognized that these observation times in vitro are 
short considering that good fertility is maintained in chickens for 5 to 6 days after mating and that some fertile eggs may be obtained as late as 35 days thereafter (Sturkie, 1965). Nevertheless, these results point to a probable differential osmotic vulnerability of fowl spermatozoa with respect to motility and fertilizing capacity.

Re-concentration. Because the usual practice with fowl is to inseminate 0.05 to $0.10 \mathrm{ml}$ of highly concentrated spermatozoa (undiluted or diluted $1: 2$ ), immediately after collection, dilute suspensions of spermatozoa in this study were generally re-concentrated by centrifugation before insemination. The morphological changes seen following centrifugation may, however, negate the advantages of inseminating small volumes. Comparison of the fertilization rates in Table 2 for dilute $(56.3 \%)$ and re-concentrated (26.5\%) spermatozoa indicates a significant difference at the $P=0.02$ level. This suggests that, for the glycine-citrate buffer, centrifugation is detrimental, provided that, for the dilute suspension, at least $80 \times 10^{6}$ spermatozoa can be inseminated in a volume of about $1 \mathrm{ml}$. Although the reverse may appear to be true for the spermatozoa in modified Krebs' solution and in glycine-phosphate buffer (Table 2), the differences are not significant $(P>0 \cdot 10)$.

\section{ACKNOWLEDGMENTS}

The support of the U.S. Atomic Energy Commission, Lawrence Radiation Laboratory (W 7405-eng-48), and the Department of Poultry Husbandry, University of California, Berkeley, is gratefully acknowledged.

\section{REFERENCES}

Bhattacharya, B. Ch. (1962) Die verschiedene Sedimentationsgeschwindigkeit der X- und YSpermien und die Frage der willkürlichen Geschlechtsbestimmung. Z. wiss. Zool. 166, 203.

Burrows, W. H. \& Quins, J. P. (1939) Artificial insemination of chickens and turkeys. Circ. U.S. Dep. Agric. 525.

GoldsteIn, A. (1964) Biostatistics: an introductory text. MacMillan, New York.

LoRenz, F. W. (1959) Reproduction in the domestic fowl: Physiology of the male. In: Reproduction in Domestic Animals, Vol. 2. Eds. H. H. Cole and P. T. Cupps. Academic Press, New York.

Pistenma, D. A. (1970) Biophysical studies of spermatozoa. Ph.D. thesis, University of California, Berkeley.

Pistenma, D. A., Mel, H. C. \& Snapir, N. (1971) Biophysical characterization of fowl spermatozoa. II. Interrelationships between intrinsic motility and electrophoretic mobility. F. Reprod. Fert. 24, 161 .

Sturkie, P. D. (1965) Avian physiology, 2nd edn. Cornell University Press, Ithaca, New York.

VAn Wambeke, F. (1967) The storage of fowl spermatozoa. I. Preliminary results with new diluents. 7. Reprod. Fert. 13, 571. 